
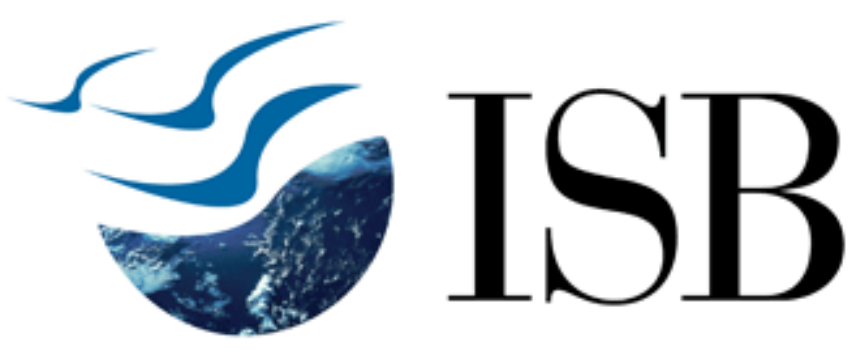

\title{
Letting the Briber Go Free: An Experiment on Mitigating Harassment Bribes
}

http://eprints.exchange.isb.edu/86

Working Paper

Indian School of Business

2013 


\title{
Letting the Briber Go Free: An Experiment on Mitigating Harassment Bribes
}

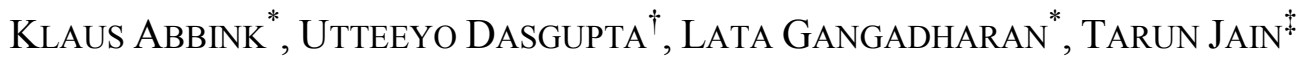

\section{September 2013}

\begin{abstract}
This paper examines the effectiveness of using asymmetric liability to combat harassment bribes. Asymmetric liability is a mechanism where bribe-takers are culpable but bribe-givers have legal immunity. Results from our experiment indicate that while this policy has the potential to significantly reduce corrupt practices, weak economic incentives for the bribe-giver, or retaliation by bribetakers can mitigate the disciplining effect of such an implementation. Asymmetric liability on its own may hence face challenges in the field.
\end{abstract}

Keywords: Harassment bribes, Experiment, Asymmetric Penalty, Retaliation.

JEL Classification: C91, K42.

\footnotetext{
*Department of Economics, Monash University.

${ }^{\dagger}$ Department of Economics, Franklin and Marshall College.

${ }^{\ddagger}$ Finance, Economics and Public Policy Area, Indian School of Business.

We gratefully acknowledge financial support from Monash University and the Indian School of Business. We thank Antonio Callari, David Owen, David Huffman, John Smith, Martin Dufwenberg, Subha Mani and participants of the ESA meetings at NYU, Germany, and workshop participants at CSSS Kolkata, Monash University, University of Queensland, University of Tasmania, University of Virginia, JNU, World Bank, ISI Delhi and ISB for their comments and suggestions. We also thank V. S. Rao, N. K. Sharma and Veer Singh for their help in facilitating the experiments at their respective universities. Urvashi Jain, K. Jayashree, Megha Juneja and Preethi Rao provided excellent research assistance.
} 


\section{Introduction}

Bribes (also called speed money) are not limited to situations where a citizen pays them to receive undue favors in contracts or services from public officials. Bribes are also frequently exchanged for delivering entitled services such as admission to a public hospital or approval of a passport. ${ }^{1}$ Basu (2011) characterizes the latter exchanges as harassment bribes. In this case although the officials cannot deny services legally, they can aggravate delivery or threaten to delay the service beyond a point where it becomes useless to the citizen. Harassment bribes raise the effective price of the public goods and services and reduce trust in good governance, which arguably reduces social welfare. Insofar that the poor are more likely to use public services, such bribes act as a regressive tax and prevent access to basic services. As a result, developing effective anti-bribery mechanisms is an important policy objective. While refusing to pay bribes remains an option for citizens, changing the legal framework has a potentially direct role for mitigating harassment bribes. ${ }^{2}$ This paper examines the impact of different liability regimes on the incidence of harassment bribery.

Different countries vary in the legal approaches to curbing bribery. While in the United States, United Kingdom, France, Germany and India, the bribe-giver and recipient are both equally culpable and face penalties (we call this symmetric liability), prescribed legal punishment for the bribe-giver is comparatively mild in China, Japan and Russia (see Engel, Görg and Yu 2012 for a discussion). Harassment bribery is reported to be particularly rampant in public services. Data collected over 21 months from an Indian anti-graft website

\footnotetext{
${ }^{1}$ Since the seminal work by Rose-Ackerman (1978) on corruption, economists have been interested in this area (Shleifer and Vishny 1993, Mauro 1995, Bardhan 1997, van Rijkeghem and Weder 2001, Rose-Ackerman 2006, Rose-Ackerman and Soreide 2011).

2“A novel way to combat corruption: Who to punish”, The Economist, May $5^{\text {th }} 2011$.
} 
(www.ipaidabribe.com) showed that about half a billion rupees were paid in bribes to lodge police complaints, receive land purchase documents, marriage certificates, electricity connections or registration documents for home purchases. ${ }^{3}$ Transparency International (2012) ranks India 94th amongst 176 countries and finds that citizens pay bribes especially in dealing with health and tax sectors, real estate, legal courts and the police. Transparency International's (2013) report on bribery in India points out that $54 \%$ of citizens report paying bribes for common government services, and that $80 \%$ of these bribes were paid to avoid harm rather than to gain any advantage. The current legal environment in many countries, which features symmetric liability for both the bribe-giver and receiver, seems to further exacerbate this situation. The typical bribe-giver, who is an ordinary citizen, is in a dilemma when faced with a bribe demand from a public official. Refusal to pay implies considerable inconvenience or loss due to a certain delay in receiving the service, while succumbing to bribe-giving makes her legally culpable should the transaction be discovered.

To remedy this situation, Basu (2011) suggests a punishment system with asymmetric liability, prosecuting and punishing only the public official (bribetaker) and imposing no legal liability for the ordinary citizen seeking the service (bribe-giver). ${ }^{4} \mathrm{He}$ hypothesizes that offering the citizen legal impunity for whistle-blowing even if she has paid a bribe can encourage more frequent reporting. In turn, this should discourage officials from demanding bribes in

\footnotetext{
3 "Rs. 11.42 crore and counting... Is what Bangalore paid in bribes", The Times of India, June $6^{\text {th }}$, 2012. These kinds of bribes are observed in many other parts of the world as well. For example, about $44 \%$ of parents in several African countries were asked to pay bribes for admission to public schools for their children, (Transparency International, 2010).

${ }^{4}$ A citizen feedback model being trailed in Pakistan (Callen and Hasanain, 2011) and Ghana's whistleblower act (Amegashie, 2013) have some similar features, with protection being granted to citizen whistleblowers and measures taken to empower them by registering their complaints.
} 
anticipation of the whistle-blowing. Consequently, Basu predicts reduced incidence of harassment bribery in equilibrium. ${ }^{5}$

Critics of Basu's proposal argue that impunity for givers would make bribery morally acceptable, discourage refusals of bribe-demands, and as a result, increase the incidence of bribe-giving instead of reducing it (Drèze 2011). From a practical perspective, Drèze also points out that refunding bribes can be complicated and difficult, and that feeble prosecution rates and slow delivery of justice in developing countries such as India are significant barriers that will discourage citizens from reporting bribe demands. Further, due to lax enforcement, bribe-givers after reporting will be apprehensive of future harassment if the official is still in office, and therefore, refrain from whistle-blowing.

This paper uses experiments to examine the effectiveness of the asymmetric liability mechanism in combating harassment bribes. Our experimental approach offers an alternative to traditional survey or field data analysis. We present a typical harassment bribe scenario in a stylized game played by participants in a laboratory. By varying the institutional environment across treatments, we can identify conditions under which policy measures may or may not work. The laboratory allows us to observe corrupt decisions empirically, an endeavor that is notoriously difficult in the field since everybody involved in such decisions has good reasons to remain silent.

While the effect of leniency programs has previously been studied in the context of antitrust policies (Apesteguia et al. 2007; Bigoni et al. 2012), only

\footnotetext{
${ }^{5}$ Policymakers in other countries have attempted such asymmetric liability rules in contexts other than corruption. For example, the United States outlawed distribution and sale of alcohol during the Prohibition era (1920-33), while consumption remained legal. As a result, customers could testify against their suppliers, which would have been difficult had consumption also been illegal (Miron 1999). Sweden, followed by Iceland and Norway, introduced anti-prostitution laws with a similar spirit of asymmetric impunity.
} 
recently has this idea captured the attention of the anti-corruption literature. Dufwenberg and Spagnolo (2011) introduce a theoretical model to evaluate Basu's proposition of asymmetric penalties. They conclude that the effect of Basu's policy depends on the quality of the indigenous institutions, would work better if bureaucrats are under pressure to perform, and if citizens incur very low costs for reporting bribery. ${ }^{6}$

The growing experimental literature on corruption, starting with Abbink et al. (2002), mainly studies collusive bribery, i.e., when citizens and officials exchange favors at the cost of the public. Collusive bribes are paid to obtain a favorable service that the briber is not entitled to. Subsequent work uses this basic structure to answer corruption related questions and test policy instruments such as staff rotation (Abbink 2004), top-down vs. bottom-up monitoring (Serra 2012), four-eye principle (Schickora 2011), and the use of bribes to motivate inspections (Lowen and Samuel 2012). There has also been research on the impact of framing, subject background and culture on behavior in the context of corruption (Abbink and Hennig-Schmidt 2006; Alatas et al. 2009; Barr and Serra 2009; Cameron et al. 2009; Banuri, Eckel, and Wilson 2011). For surveys relating to the experimental literature on corruption, see Abbink (2006) or more recently Banuri and Eckel (2012) and Serra and Wantchekon (2012).

The paper most akin to ours is the study by Engel, Görg, and Yu (2011), who also compare symmetric versus asymmetric punishment regimes, albeit in the context of collusive bribery. In their bribery game, a citizen can offer a bribe to an official who can reciprocate by manipulating his decision in the citizen's favor. In this framework, the results show that asymmetric punishment increases

\footnotetext{
${ }^{6}$ Amegashie (2013) focuses on consumer complaints and its impact on social welfare when officials may be corrupt or honest. His model also separates out corruption with theft and without theft. The latter situation is akin to harassment bribes.
} 
the frequency of corrupt exchanges. However, collusive and harassment bribery fundamentally differ from one another. Under symmetric punishment, citizen and official both have an interest that their bribe-payment stays undetected. Letting the briber go free breaks this common interest. In collusive bribery, the common interest stems from the exchange of favors, and this common interest still exists even if liability is not symmetric anymore. Hence, the results from Engel, Görg, and $\mathrm{Yu}$ (2011) cannot necessarily be transferred to harassment bribes.

Our paper is novel in several ways. First, to the best of our knowledge, this is the first experiment addressing harassment bribery which is conspicuous in the public sector in many countries and has a large detrimental impact on developmental outcomes. Second, our experimental design helps us gain better insight into decision-making in the context of corruption. For instance, demands for large bribe amounts increase the costs of public services more than small amounts, so indignant citizens might be more likely to report these instead of staying quiet. Finally, the treatments examined in the paper allow us to evaluate the relative impact of monetary versus non-monetary factors that can influence the propensity for whistle-blowing.

Our findings provide qualified support for asymmetric liability as an anticorruption mechanism. When bribe-giving is legalized, reporting increases and demands for bribes decrease. However, reporting decreases when the official has the option to retaliate. Our results indicate further that refunding bribes after prosecution might not be necessary for the success of a leniency program since intrinsic motivation is the main driver of citizens' reporting behavior. Overall, our experimental findings suggest that although asymmetric impunity schemes are promising, they should be complemented with other measures to succeed as anticorruption mechanisms. 


\section{The Harassment Game}

Consider a simple sequential-decision game between an official and a citizen for the delivery of a service that the latter is entitled to. The official is obliged to grant the service, but de facto has the discretion to deny it, or delay it indefinitely. This gives him the opportunity to demand a bribe for speedy delivery. The citizen can refuse to pay, but this is very costly. The game below is purposefully parsimonious to allow us to shed light explicitly on the efficacy of asymmetric liability as described by Basu (2011), and evaluate some of the associated concerns.

Figure 1 describes the harassment game. In stage 1, the official can either provide the service to the citizen without taking a bribe $(B=0)$, or choose to specify a bribe amount $(B)$ to ask from the citizen. In stage 2 , if the official asks for a bribe, then the citizen can choose any of the three actions: (1) refuse to pay the bribe, (2) pay quietly, or (3) pay and report the bribe. Actions (2) and (3) lead to a probabilistic discovery of bribery and the final payoffs in these two cases depend on whether the act was discovered or not. The act of bribery is more likely to be discovered if the citizen has reported the demand.

We conduct two treatments with the above set-up. The treatments differ in the payoffs the players receive for their actions. First, in a symmetric liability treatment, both citizen and official are fined if caught. This represents the legal status quo in most countries, including India where our study was conducted. In a contrasting asymmetric liability treatment, only the official gets prosecuted and pays a fine while the briber enjoys impunity and gets back his bribe. Clearly, in the latter case, the bribe-giver is no longer discouraged from reporting a bribe demand, and in fact has a strictly positive incentive to report. This, in turn, should deter the official from asking for bribes. 
To examine potential obstacles in the way to a successful implementation of the impunity scheme above we conduct two additional treatments. To address the concern about spiteful retaliation from the official's side, the first of our additional treatments introduces retaliation in the asymmetric liability scenario; now officials who escape conviction even after being reported can retaliate and reduce the citizen's payoff. In our game although retaliation is costly to the official, its mere availability might dissuade citizens from reporting bribe demands if they anticipate spiteful actions from the official. The second of our additional treatments addresses the practicality of bribe-returns to the citizen. We implement the asymmetric liability framework with bribes no longer returned, while officials continue to have the option of retaliating if conviction fails after whistle blowing. Since monetary incentives to report bribe demands are removed, this last treatment poses the toughest behavioral challenge to asymmetric liability proposal among the four situations.

We next describe the four games (Symmetric, Asymmetric, Retaliation and No-Refund) in detail along with the payoffs and experiment parameters.

\subsection{The Symmetric treatment}

Figure1 presents the extensive form of the game. First, the official decides whether or not to demand a bribe. If he does not demand a bribe, the game ends and both players receive a payoff of 500 Indian rupees (Rs.). This outcome is the most efficient (in terms of joint payoff for the citizen and the official) and also equitable. Hence, it is salient that this is the socially preferred outcome.

If the official asks for a bribe, he also needs to specify how much to ask for in multiples of Rs. 10 up to a maximum of Rs. 200. The citizen has three options: 
"Refuse to pay", "Pay quietly", or "Pay and report". Refusing to pay the bribe is extremely costly for the citizen. In particular, the citizen's payoff drops to Rs. 50, while the official retains 450 rupees, and the game ends. The decrease in the official's payoff is motivated by detrimental effects that bribery has on social efficiency, which we wanted to capture in our design. These detrimental effects have been previously captured in bribery experiments by imposing payoff reductions on other players in the lab (Abbink et al. 2002; Barr and Serra 2009; Cameron et al. 2009) or charities (Frank and Lambsdorff 2010). For our game, this approach did not seem appropriate since in contrast to collusive bribes, harassment bribes, it can be argued, have less of an immediate effect on a third party. Yet the long-run detrimental effects of bribery, such as the loss of trust in good governance is undeniable. Each act of bribery contributes to those damages, and everybody including those participating in bribery, suffers from them. ${ }^{7}$ Hence, to capture these features in our game, we reduce the total payoffs available to the two players when the official asks for a bribe, and thus impose an overall decrease in social efficiency. We further wanted to keep the game as simple as possible, hence we chose this way of implementing the harmful effects of corruption. ${ }^{8}$

If the citizen chooses to either pay quietly or pay and report the bribe, the game enters the next stage. Then a lottery determines whether the act of bribery is detected and fines are imposed. The probability of detection and prosecution depends on whether the citizen has reported the bribe exchange. If the citizen has paid quietly, then there is only a small chance that the act is discovered which we

\footnotetext{
${ }^{7}$ In fact if the official holds a monopoly on access to a particular service (such as public health care or passport delivery), the possibility of corruption could potentially raise the price of necessary services, and further inhibit mutually beneficial exchanges, leading to some distortions.

${ }^{8}$ Since our experiment is one-shot, simplicity is of particular value in our design.
} 
set to 5 percent. Paying and reporting increases this probability to 40 percent. $^{9}$ Note that even if a bribe payment is reported, detection and consequent punishment are far from certain. ${ }^{10}$

If detected however, officials are fined in the symmetric as well as the asymmetric treatments. For the experiment to be meaningful, we needed to parameterize such that behavioral effects can show up in either direction in each treatment. We conjectured that a monetary fine of Rs. 250, leading to a final payoff of Rs. 200 for each player in case of prosecution, would achieve this. Our chosen fine, along with the detection probabilities reflect the current situation in India, where they do not serve as an optimal deterrence mechanism (Debroy and Bhandari 2012), i.e., they are high enough to serve as a deterrent, and yet not so high that expected payoffs become so trivial that no one would consider engaging in bribery. The only difference between the symmetric and subsequent asymmetric treatments is that citizens do not pay a fine in the asymmetric treatments.

A simple backward induction analysis of the game suggests that the monetary incentives are such that the citizen faced with a bribe demand will always pay quietly. The official anticipates this and chooses his best response demand the maximum possible bribe.

\footnotetext{
${ }^{9}$ The probability of detection chosen is conservative but realistic as empirical estimates suggest that the fraction of reported bribe payments that leads to penalties is about $40 \%$ or slightly less in India (National Crime Records Bureau 2010).

${ }^{10}$ Tummala (2009) in a careful documentation of prevalent corruption in India suggests that although there are a plethora of government bodies that have been setup over the years, the law remains vague and open to different interpretations about the nature of punishment. In particular, section 165 of the Indian Penal Code states the punishment for bribery as follows, "....shall be punished with imprisonment ... for a term which may extent to three years, or with fine, or with both."
} 


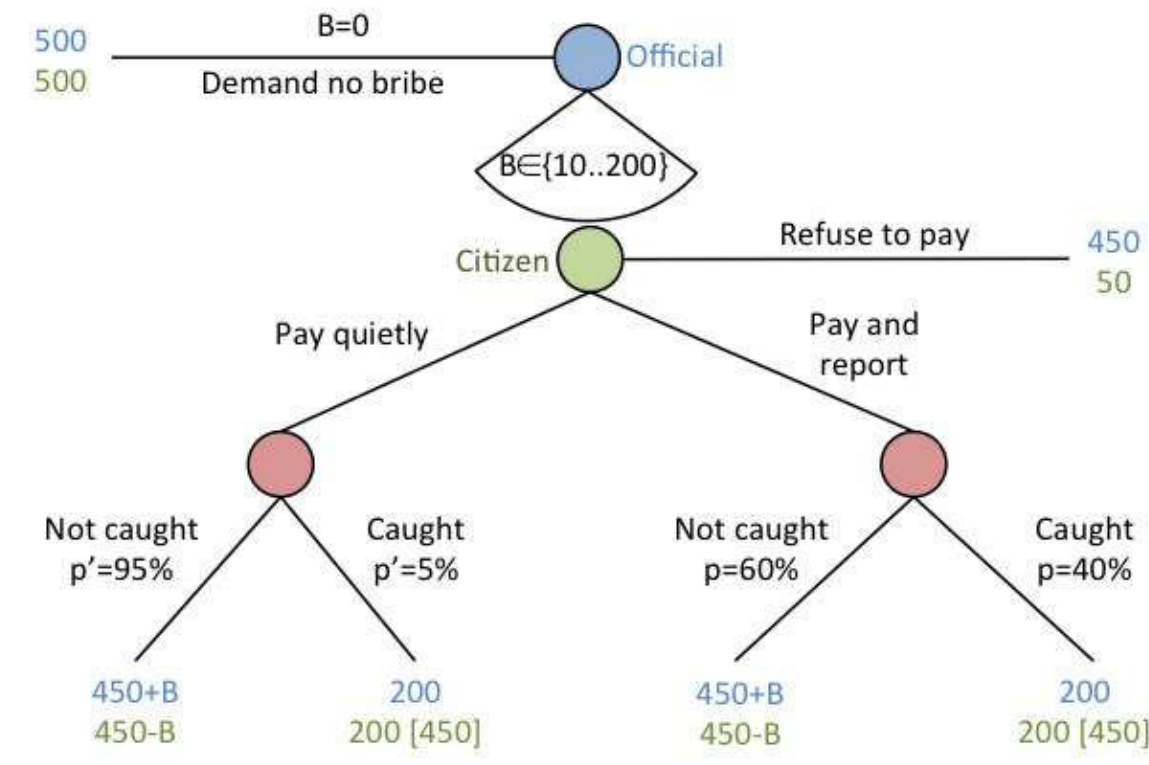

SYMMETRIC and ASYMMETRIC*

The payoffs in square brackets [] denote the changes in payoffs in ASYMMETRIC

Figure 1. The game tree - treatments without retaliation

\subsection{The Asymmetric treatment}

This treatment introduces the briber leniency approach (as proposed by Basu 2011), and as mentioned before, differs from the symmetric treatment only in the treatment of the citizen in case of detection. Here, only the official is fined (the same amount as in the symmetric treatment). ${ }^{11}$ The citizen is not held responsible and the bribe she has paid is returned to her. Consequently, monetary incentives change now in a way that the citizen would always like to report if she is asked for a bribe. The backward induction logic in turn predicts that officials will shy

\footnotetext{
${ }^{11}$ Basu (2011) originally proposed that the fines for the official be doubled to keep the overall fine the same. We did not implement this because it would have been difficult to separate effects of the leniency program from effects of the higher fine.
} 
away from demanding bribes, since not asking for a bribe is his best response to the citizen's "pay-and-report" choice. Hence, we should observe no bribes demanded in equilibrium. Figure 1 above summarizes the extensive form of the above two treatments.

\subsection{The Retaliation treatment}

The analysis above provides sufficient optimism on the deterrent effect of the leniency program, at least in theory. In reality, however, a relatively low conviction rate might discourage whistle-blowing considerably, especially if the citizen is apprehensive of further harassment from the official in the future. In this case, the prospect of getting the bribe back after successful prosecution must be weighed against potential retaliation if the prosecution is unsuccessful, leading to the official to remain in office. We consider such a situation in the retaliation treatment where the official has the option to be spiteful and reduce the citizen's payoff if whistle blowing is unsuccessful. We assume though that the official needs to incur costs to do so. In particular, the official has to spend Rs. 50 to reduce the citizen's final payoff by Rs. 150 . This ratio (1:3) of cost to damages is consistent with previous experiments in which punishment options were studied (Gächter et al. 2008).

Since it is costly, an official would never retaliate in the sub-game on the basis of monetary payoff gains alone. Hence, the theoretical money-maximizing equilibrium prediction remains as before, no-bribery in equilibrium. A plethora of previous experiments however suggest that retaliation even if costly, is carried out often; sometimes to encourage socially desirable outcomes (Gächter et al. 2008), and sometimes to enforce outcomes that are socially inefficient (Abbink et al. 2010). Hence, we conjecture that even though not a part of the sub-game perfect 
equilibrium, a behavioral threat of retaliation can be credible and possibly diffuse the deterrent effects of the leniency program.

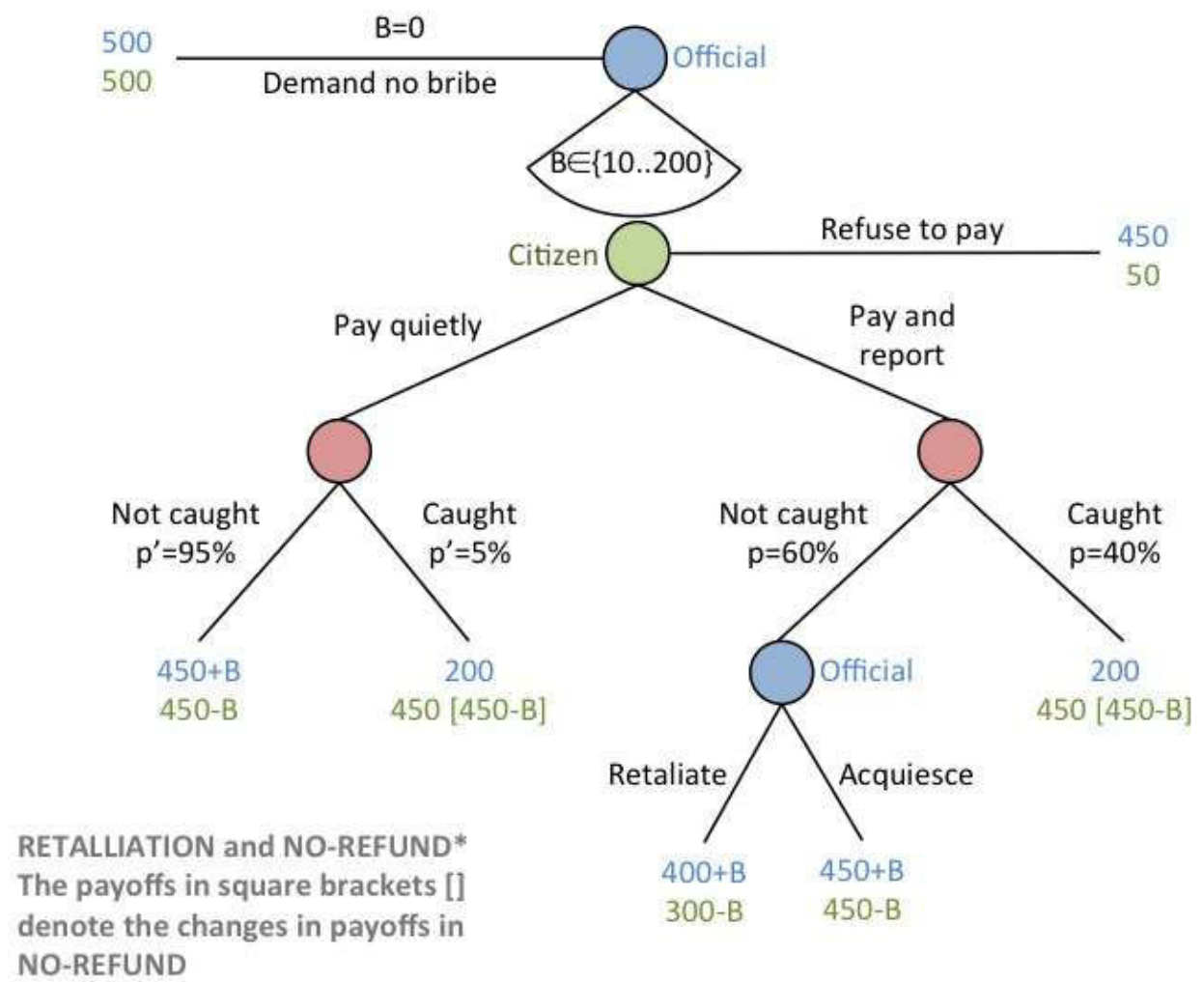

Figure 2. The game tree - treatments with retaliation

\subsection{The No Refund treatment}

On paper, our fourth treatment provides the toughest challenge for the asymmetric liability mechanism. The theoretical analysis of the game, as described by Basu (2011), relies heavily on monetary incentives offered to the citizen to come forward and report a bribe. In particular, the prospect of getting her bribe money back when the official is convicted creates the positive incentive to self-report. However, this feature might be naïve as, in reality, bribers rarely get a receipt for their payment so verifying the exact amount that changed hands is difficult. 
Therefore, in practice a leniency program is more likely to rely on the citizen's intrinsic motivation to report a bribe. Such motivations can exist, and in fact a citizen who is sufficiently upset about the unfairness and immorality of the situation might be willing to report even without the incentive of material benefits. ${ }^{12}$ The victim can also consider taking action if she believes to be serving a greater societal benefit. ${ }^{13}$

The no-refund treatment allows us to examine whether a leniency policy can work in the absence of monetary incentives. The treatment differs from the retaliation treatment only in the citizen's payoff in case of the successful prosecution of the official. We retained the opportunity for officials to retaliate in this treatment to design an extreme case scenario in which citizens would face the threat of retaliation and also not have any monetary incentive to report. We introduce payoffs for the citizen such that it is not strictly better for the citizen to report a bribe as she does not get back the bribe even if whistle blowing turns out to be successful. The equilibrium prediction is now indeterminate. The citizen is indifferent between paying quietly and reporting the bribe payment. ${ }^{14}$ As a result, multiple sub-game perfect Nash equilibria are possible, and behavior in the experiment can offer some insight on preferred equilibrium behavior. Figure 2 describes the extensive form of the above two treatments. Table 1 summarizes the design features and predictions of the four treatments.

\footnotetext{
${ }^{12}$ See for example, citizen efforts in reporting bribes in India through the web portal www.ipaidabribe.com.

${ }^{13}$ In that case, one might even envision a situation where monetary incentives for whistle-blowers would prove to be counterproductive if such extrinsic motivations have a tendency to crowd out intrinsic motivations (Frey and Oberholzer-Gee 1997).

${ }^{14}$ It may even be costly for the citizen to report, in which case the citizen would have a strict incentive not to report. We abstracted from such costs, assuming a situation where reporting facilities are put in place that make reporting costs trivial. Our goal was to study the effectiveness of leniency out of pure intrinsic motivation, where there are no monetary incentives for or against reporting.
} 
While several alternative treatments relating to corruption would be interesting to examine using the above framework, we restricted our attention to scenarios that are specific to harassment bribes and are currently being considered in the field in different parts of the world.

Table 1. Treatments

\begin{tabular}{lll}
\hline \hline Treatment & Description & Predicted bribe demands \\
\hline \hline 1. Symmetric & $\begin{array}{l}\text { Official and Citizen both liable and pay } \\
\text { penalty; bribe refunded. }\end{array}$ & $100 \%$ \\
2. Asymmetric & $\begin{array}{l}\text { Only Official liable and pays penalty; } \\
\text { bribe refunded. }\end{array}$ & $0 \%$ \\
3. Retaliation & $\begin{array}{l}\text { Only Official liable and pays penalty; } \\
\text { bribe refunded; Official can retaliate. }\end{array}$ & $\begin{array}{l}\text { Only Official liable and pays penalty; } \\
\text { 4. No Refund }\end{array}$ \\
& $\begin{array}{l}\text { bribe not refunded; Official can } \\
\text { retaliate. }\end{array}$ & Indeterminate \\
\hline
\end{tabular}

\subsection{Behavioral Predictions}

The theoretical predictions laid out in the previous subsections are derived assuming pure own-income maximization, which is standard game theoretic reasoning. In a morally loaded context like corruption, payoffs perceived by the agents may not be only monetary. For instance, citizens and officials may weigh potential material gains against their discomfort from engaging in immoral acts. So, citizens' best responses may be to refuse to pay even if it is monetarily costly and officials may optimally forego profitable bribe opportunities. If we take these considerations into account, then the equilibrium predictions become less clearcut. However, as we shall see, we still find that asymmetric liability should encourage reporting.

Consider the citizen's decision problem. Following the classic approach by Rose-Ackerman (1975), we model attitudes to bribery as moral costs that are 
incurred when engaging in corrupt acts. We assume that refusing does not incur moral costs (or equivalently, normalize them to zero). Let $\mathrm{C}_{\mathrm{P}}$ be the moral cost of paying quietly and $C_{R}$ be the moral cost of paying and reporting. Note that we cannot a priori say which one is greater. For instance, a citizen might feel $C_{R}<C_{P}$, because she has done the right thing and reported a corrupt official, or $C_{R}>C_{P}$ if the citizen is averse to turning in another person even if it is a corrupt official. In the treatments with retaliation, the citizen must also take into account the subjective probability that the official retaliates, which we denote by q. Table 2 lists the payoff lotteries a citizen receives when choosing one of the three options, considering the moral costs.

Table 2. Payoffs with moral costs

\begin{tabular}{llll}
\hline & Pay quietly & Pay and report & Refuse \\
\hline Symmetric & $200-\mathrm{C}_{\mathrm{P}}$ with $5 \%$ & $200-\mathrm{C}_{\mathrm{R}}$ with $40 \%$ & 50 \\
& $450-\mathrm{B}-\mathrm{C}_{\mathrm{P}}$ with $95 \%$ & $450-\mathrm{B}-\mathrm{C}_{\mathrm{R}}$ with $60 \%$ & \\
\hline \multirow{2}{*}{ Asymmetric } & $450-\mathrm{C}_{\mathrm{P}}$ with $5 \%$ & $450-\mathrm{C}_{\mathrm{R}}$ with $40 \%$ & 50 \\
& $450-\mathrm{B}-\mathrm{C}_{\mathrm{P}}$ with $95 \%$ & $450-\mathrm{B}-\mathrm{C}_{\mathrm{R}}$ with $60 \%$ & \\
\hline \multirow{2}{*}{ Retaliation } & $450-\mathrm{C}_{\mathrm{P}}$ with $5 \%$ & $450-\mathrm{C}_{\mathrm{R}}$ with $40 \%$ & 50 \\
& $450-\mathrm{B}-\mathrm{C}_{\mathrm{P}}$ with $95 \%$ & $450-\mathrm{B}-\mathrm{C}_{\mathrm{R}}$ with $(1-\mathrm{q}) \cdot 60 \%$ & \\
& & $300-\mathrm{B}-\mathrm{C}_{\mathrm{R}}$ with $\mathrm{q} \cdot 60 \%$ & \\
\hline No refund & $450-\mathrm{B}-\mathrm{C}_{\mathrm{P}}$ & $450-\mathrm{B}-\mathrm{C}_{\mathrm{R}}$ with $40 \%+(1-\mathrm{q}) \cdot 60 \%$ & 50 \\
& & $300-\mathrm{B}-\mathrm{C}_{\mathrm{R}}$ with $\mathrm{q} \cdot 60 \%$ & \\
\hline
\end{tabular}

Comparing the expected values of the lotteries (assuming risk neutrality), we can derive conditions for the values of the moral costs required to make one of the options optimal. If we compare pay quietly to pay and report in the symmetric case, we obtain that paying quietly is better than reporting if

$$
\mathrm{C}_{\mathrm{R}}-\mathrm{C}_{\mathrm{P}}>0.35 \mathrm{~B}-87.5
$$


Reporting is only preferable if the costs of paying quietly are much higher than the costs of reporting, or if the bribe demand is very high. In the asymmetric treatment, paying quietly is better than reporting if

$$
C_{R}-C_{P}>0.35 B
$$

Now the citizen would choose not to report only if she has a strong aversion to turning in somebody. Note that regardless of what $C_{R}$ and $C_{P}$ are, a citizen who reports under symmetric liability will always report in the asymmetric case. Thus, even when citizens feel averse to reporting, we should still expect more (or at least as much) reporting under asymmetric liability than under the symmetric status quo.

In the Retaliation treatment, the condition becomes

$$
C_{R}-C_{P}>0.35 B-90 q
$$

If the citizen does not expect any retaliation, then this is identical to the asymmetric treatment $(\mathrm{q}=0)$, otherwise reporting becomes, as expected, less attractive as the subjective probability of retaliation increases. Note that for the parameters of our experiment, we still expect at least as much reporting with retaliation as in the symmetric baseline, except for extremely high perceived retaliation probabilities $(\mathrm{q}>87.5 / 90=97.2 \%)$.

In the no-refund treatment, the citizen prefers paying quietly over reporting if

$$
C_{R}-C_{P}>-90 q
$$


Thus, if no retaliation is expected, the optimal decision solely depends on which action incurs the greater moral costs. Not surprisingly, reporting becomes less attractive as the citizen assesses higher threats of retaliation. ${ }^{15}$

\section{Procedure}

All experimental sessions were conducted in Hyderabad, India, with undergraduate and graduate (Masters) students. Three hundred and sixty subjects participated in the experiment. Subjects were recruited by sending email invitations to the student association listservs in each of three prominent institutes in the city - BITS Pilani's Hyderabad Campus, NALSAR Law University and the University of Hyderabad. We selected these institutions since they enroll students from all over India allowing us to recruit a subject group with a range of backgrounds. All four treatments were conducted in each institution. Each subject participated in only one of the treatments.

No economics experiments have been conducted at any of these institutions before, so contamination from one session to another was a potential concern. Since anonymous recruiting systems were not in place, participants in later sessions could potentially be influenced by what they heard from participants in earlier sessions. To rule out such effects, the experiment was conducted in a single afternoon at each location. We held two large sessions with 60 subjects

\footnotetext{
${ }^{15}$ We do not derive a full-fledged equilibrium analysis including the officials' best responses. Extending the analysis in this way is straightforward, but can be very lengthy, as many cases need to be considered. The official's optimal bribe demand depends on his expectation of the reporting probability, which depends on the distribution of moral costs he expects in the population of citizens, and his own moral costs of demanding a bribe. However, all other things equal, the payoff structure of the game implies that bribe demands become less attractive if the probability of reporting crowds out the probability of paying quietly. Hence, we would expect that a policy that encourages reporting should not increase the frequency of bribe demands, but likely decrease it.
} 
back-to-back, with the second session starting while the participants of the first session were still in the classroom. All subjects first met in a large lecture theatre and were given general instructions. They were then divided into two groups of 30 subjects and led to one of two classrooms where we had prepared visual separation between the desks. The two groups participated in different treatments, which we conducted simultaneously. Detailed instructions were given by an instructor and to avoid possible experimenter effects, which might stem from the inevitable use of different instructors for the different groups, we made sure that the assignment of instructors to treatments was as balanced as possible.

Subjects within each group were randomly assigned to the role of an official or a citizen. The experimenter read the instructions aloud. Our objective was to simulate the context of a corrupt transaction and evoke associated emotional and moral responses. Therefore, we used in-context language consistently throughout the instructions (see the experimental instructions in the appendix). ${ }^{16}$ The use of context-specific instructions also improves the external validity of our results. Furthermore, we used real currency in the experiments ensuring that participants could comprehend and relate to the decision making more easily.

Subjects were asked to fill in their decision sheet where they made decisions for every situation they could be in during the game. We chose to elicit complete strategies for two reasons. First, this method allows us to gather decisions for all possible decision nodes, including those that are not reached in realized play. This increases data-effectiveness dramatically. Second, strategy

\footnotetext{
${ }^{16}$ There is mixed evidence about the impact of context specific instructions in corruption experiments. While Barr and Serra (2009) find that bribes are less likely to be offered and accepted in the laboratory when the experimental instructions explicitly describe a bribery scenario instead of a more abstract description, Abbink and Hennig-Schmidt (2006) and Krajcova and Ortmann (2008) find no significant differences between neutral and bribery frames.
} 
elicitation compresses the multi-stage game into one with a single simultaneous move for each player. Our time-constrained setting did not allow us to shift decisions back and forth between the players. ${ }^{17}$

After the experiment was over, subjects completed a survey questionnaire first before collecting their experiment earnings. To compute earnings, the decision sheet for each official was randomly matched with a citizen who participated in the same treatment at the same location. Based on the decisions of each player, the payoffs were calculated and distributed to participants in a sealed envelope. The subjects earned an average of Rs. 493. At the time of the experiment, the exchange rate to other major currencies was approximately 1.95 US dollars, 1.54 euro and 12.50 Chinese Yuan for 100 Indian rupees.

\section{Results}

\subsection{Survey Results}

We find that even though our subjects were relatively young (average age of 22 years), $55 \%$ admitted to paying a bribe to obtain household services such as electricity, water or a telephone connection, financial services in a bank, post office, insurance company or transport office and educational services at a school or college. Additionally, participants seemed to be well aware of anti-corruption laws in India, with 63\% reporting "If caught, both the bribe giver and taker are committing an illegal act". They also report feeling uneasy about bribery, with only $22 \%$ supporting the statement, "Do you think that it is useful to have a system where there is a way to get what you want even if you have to bribe". The

\footnotetext{
${ }^{17}$ Brandts and Charness (2011) survey experiments that have been conducted with both strategy elicitation and spontaneous play. While magnitude effects can sometimes be found, no study reports that treatment comparisons would be affected.
} 
data from the survey indicates that the subject pool was reasonably informed, had some exposure to corruption and had views and concerns about it, enabling an accurate examination of the effectiveness of different corruption policies. Note that subjects answered these questions at the end of the experiment after all experiment decisions had been made.

\subsection{Experimental Results}

We organize our results below in terms of the two players and their behavior. Citizens' actions are reported first, since leniency proposals are directly aimed at changing their behavior. Officials' anticipatory behavior is reported next.

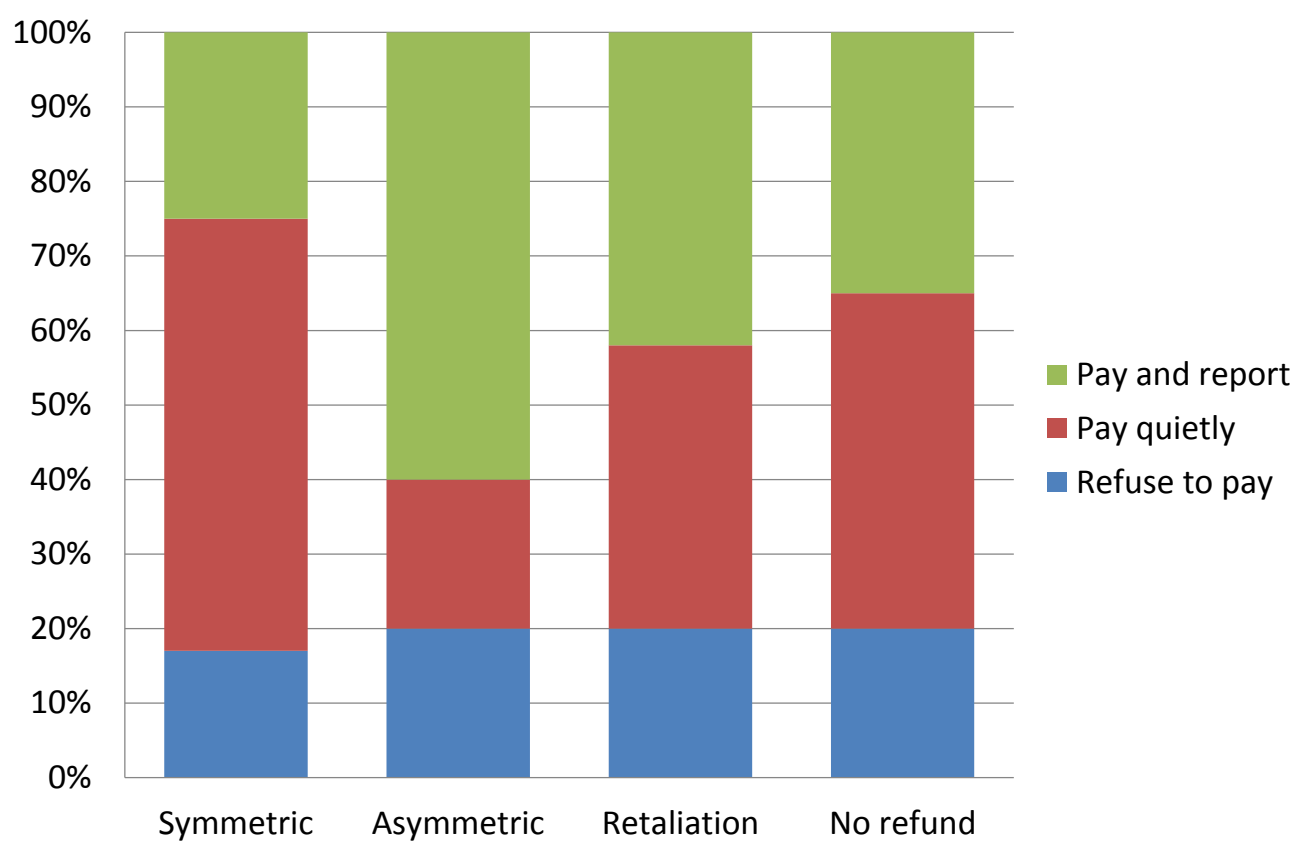

Figure 3. Citizens' decisions - all bribe offers 


\section{Do Citizens report under impunity?}

Figures 3 and 4 show the percentage of subject decisions that were "Pay and report", "Pay quietly" and "Refuse to pay" in each of the four treatments. We find that consistent with the predictions earlier (as well as Basu's proposal), the percentage of citizens who pay and then report the bribe-demand jumps from $25 \%$ to $59 \%$ under the asymmetric liability policy (a Mann-Whitney test rejects the null of equal means with $\mathrm{p}$-value $=0.001$ ). Note that the increase in this percentage is not due to any perceptible change in the percentage of subjects who refuse to pay the bribe (see Figure 3). Rather it is caused by the decrease in the percentage of citizens who pay quietly ( $58 \%$ to $19 \%)$.
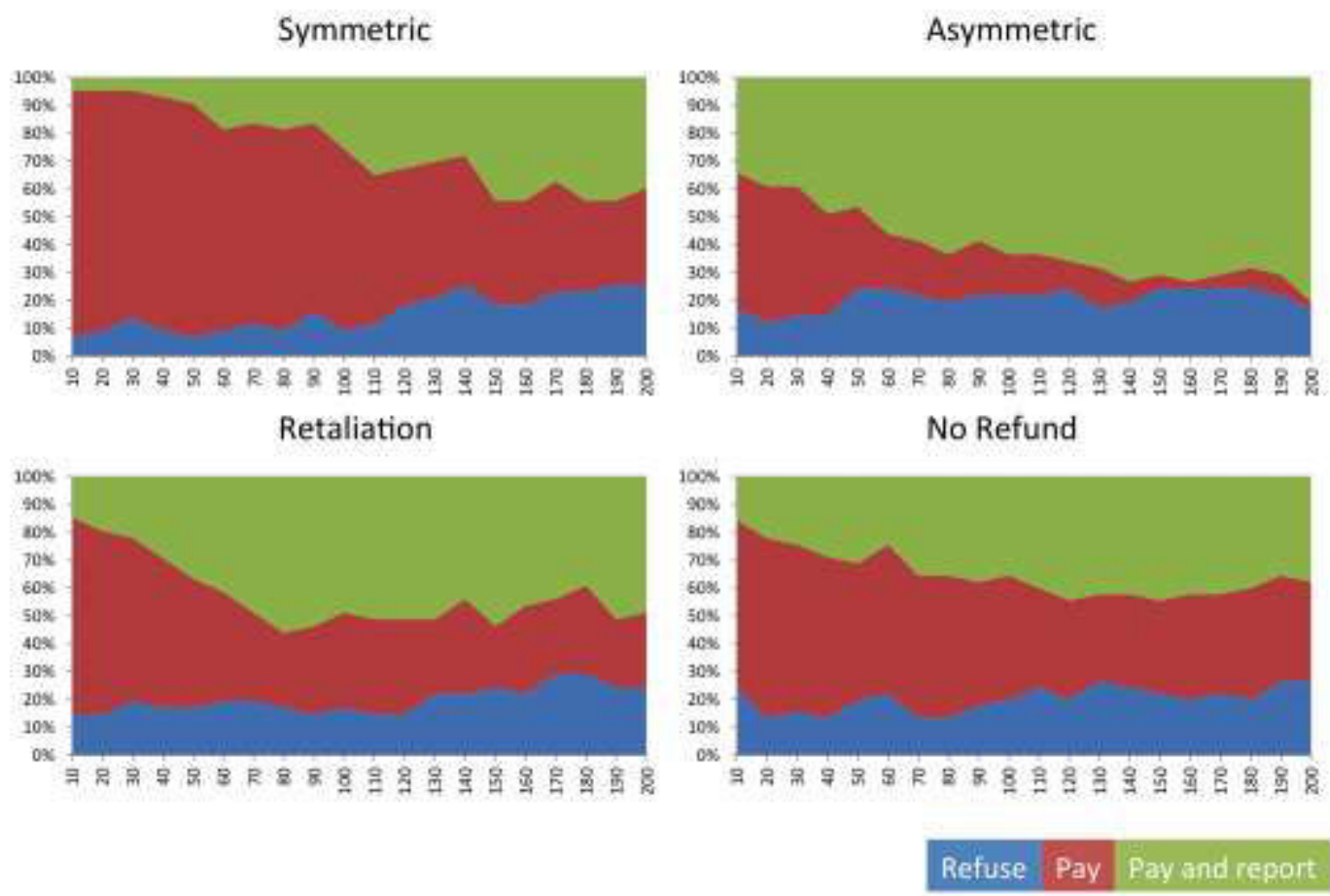

Figure 4. Citizens' decisions conditional on bribe demanded 
Table 3: Multinomial logit estimates of citizen decisions

\begin{tabular}{lllll}
\hline & \multicolumn{2}{l}{ Refuse to pay } & \multicolumn{2}{l}{ Pay quietly } \\
\cline { 2 - 5 } & RRR & Std. Err. & RRR & Std. Err. \\
\hline Bribe amount in symmetric treatment & 1.000 & 0.002 & $\mathbf{0 . 9 9 5 * * *}$ & 0.002 \\
Bribe amount in asymmetric treatment & 0.996 & 0.002 & $\mathbf{0 . 9 7 7 * * *}$ & 0.003 \\
Bribe amount in retaliation treatment & 0.999 & 0.002 & $\mathbf{0 . 9 8 9 * * *}$ & 0.002 \\
Bribe amount in no refund treatment & 1.000 & 0.002 & $\mathbf{0 . 9 9 2 * * *}$ & 0.002 \\
NALSAR & 1.371 & 0.507 & 0.876 & 0.214 \\
University of Hyderabad & $\mathbf{4 . 2 4 4 * * *}$ & 1.42 & 0.974 & 0.261 \\
Hindu & 1.306 & 0.540 & 1.144 & 0.306 \\
Scheduled Caste & 0.817 & 0.345 & 1.072 & 0.345 \\
Male & 1.113 & 0.332 & 1.373 & 0.300 \\
\hline
\end{tabular}

Chi-square test for mean treatment differences when choice $=$ Refuse to pay

(Bribe amount in) symmetric treatment $=$ asymmetric treatment $\quad p$-value $=0.18$

(Bribe amount in) asymmetric treatment $=$ retaliation treatment $\quad$ p-value $=0.35$

(Bribe amount in) retaliation treatment $=$ no-refund treatment $\quad p$-value $=0.64$

Chi-square test for mean treatment differences when choice $=$ Pay quietly

(Bribe amount in) symmetric treatment $=$ asymmetric treatment $\quad p$-value $=0.00$

(Bribe amount in) asymmetric treatment $=$ retaliation treatment $\quad$ p-value $=0.00$

(Bribe amount in) retaliation treatment $=$ no-refund treatment $\quad p$-value $=0.26$

$\begin{array}{ll}\text { Pseudo R square } & 0.102\end{array}$

Number of observations $\quad 3571$

Notes: RRR is Relative risk ratio. "Pay and report" is the base outcome from the dependent variables. "BITS" is the omitted category from the independent variables. Standard errors clustered by participant. $* * * \mathrm{p}<0.01$.

The increase in reporting behavior however, goes down significantly from the asymmetric to the no-refund treatment where officials are allowed to retaliate and strict monetary incentives from reporting are removed (a Mann-Whitney test rejects the null of equal means with $p$-value $=0.01$ ). In fact, we find that the average percentage of citizens "paying and reporting" goes down towards the mean of the symmetric treatment (a Mann-Whitney test fails to reject the null of 
equal means with $\mathrm{p}$-value $=0.65$ ). These results suggest that allowing the possibility of retaliation by officials deters citizens' reporting behavior.

Further, an examination of the distribution of bribe demands suggests that irrespective of the treatment, citizens make their choices contingent on the officials' bribe demand amounts - higher bribe demands are typically met with a "pay and report" while smaller bribe demands are often paid and not reported. Figure 4 describes the subject behavior in the four treatments.

To investigate citizens' behavior in more detail, we estimate a multinomial logit model where citizens' choices are a function of the amount of bribe demanded, controlling for the education institutions as well as some of the demographic characteristics of the participants obtained from the survey. Results of this estimation are reported in Table 3. We find that irrespective of the treatment, a one-rupee increase in the bribe-demand significantly decreases the relative-risk-ratio of being in the "pay quietly" group compared to being in the base comparison group of "pay and report". For example, in the symmetric treatment, a rupee increase in the bribe-ask leads to a decrease in the relative risk of the subject being in the "pay quietly" group compared to the "pay and report" group by a factor of 0.995 (see row 1 and column 3 of Table 3), and similarly for all the other three treatments.

The results confirm our observation that across treatments, as the size of the bribe demand increases it is more likely to be reported. Put alternatively, a small amount of bribe demand is less likely to be reported. The latter observation reveals that subject behavior is suggestive of an established norm amongst the subject population where a large bribe demand is considered to be unfair, while a small bribe demand is acceptable and does not violate subjects' fairness perceptions. Consequently, we observe an element of reciprocity in citizens' choices where high bribe demands may be seen as unkind and trigger reporting. 
This is observed in the symmetric treatment where reporting a bribe demand is actually costly for the citizen, and yet high bribe-demands are typically reported. In contrast, low demands are possibly perceived as a relatively kind act from the official; so in the asymmetric treatment, when reporting the bribe demand is not costly and citizens would in fact improve their expected monetary payoffs, they tolerate low bribe demands and choose not to report.

The pairwise tests of treatment differences in Table 2 show that for the "pay quietly" option, behavior is significantly different across treatments for the first two comparisons, but not for the comparison between the retaliation and norefund treatment, suggesting that taking monetary incentives away may not affect reporting behavior significantly. These tests also indicate that consistent with Figure 4, the percentage of subjects who "refuse to pay" remain unaltered across treatments. This suggests that at least in our experiment, citizens on an average do not change their behavior due to the introduction of leniency programs that might signal moral acceptability.

\section{Do officials demand fewer bribes?}

We next examine whether giving immunity to citizens induces any anticipatory change in bribe demands by officials. Recall that according to Basu's hypothesis asymmetric liability ought to not only change citizens' behavior, but also discipline officials' bribe demands. Accordingly, the backward induction analysis in our asymmetric and retaliation games predicts that in the unique sub-game perfect Nash equilibrium, officials do not demand any bribes. Overall, in our experiment the officials seem to show a weaker response to variations across treatments compared to citizens. One possibility is that they might not be thinking in a backwardly inductive manner. Officials might also face an additional level of strategic uncertainty compared to citizens, as they have to foresee the citizens' 
response while citizens can condition their choice on the official's demand. This additional level of uncertainty can possibly dilute some of the treatment effects.

Figure 5 shows a distinct tendency towards reduction in bribe demands by officials. We find that the percentage of officials who demand a bribe drops from $38 \%$ in the symmetric liability situation to $24 \%$ in the asymmetric liability situation (a Mann-Whitney test rejects the null of equal means with $p$-value $=0.08$ ). The average bribe amount demanded by the officials also goes down from Rs. 152 to Rs. 135 rupees, although this is not statistically significant. ${ }^{18}$ The drop stems from fewer bribe demands, not the amount that is asked for. Figure 5 describes the average bribes asked in each treatment, conditional on a positive bribe demand. These averages are very similar across all treatments and no difference is statistically significant. One might hypothesize that officials may try to compensate for the higher risk of being reported under asymmetric liability by demanding higher bribes, but our data do not provide any indication for this.

When officials are allowed to retaliate, $44 \%$ chose to pay money (Rs. 50) to reduce the citizen's payoff (by Rs. 150) in the retaliation treatment and 33\% in the no-refund treatment (this difference is not statistically significant). The proportion of officials demanding bribes increases as anticipated. In fact, behavior in the retaliation and no-refund treatments suggests that the disciplinary effects of briber impunity dissipate away considerably for officials. Figure 5 shows that $38 \%$ and $27 \%$ of officials demand bribes in the two treatments. The average amount of bribes demanded are Rs. 149 and Rs. 148 respectively, lower than in the symmetric treatment but higher than the asymmetric treatment.

\footnotetext{
${ }^{18}$ Despite the high bribe amount, the overall frequency of bribes is low, with at least $62 \%$ of officials not demanding bribes. This might indicate either aversion to corruption or risk aversion.
} 


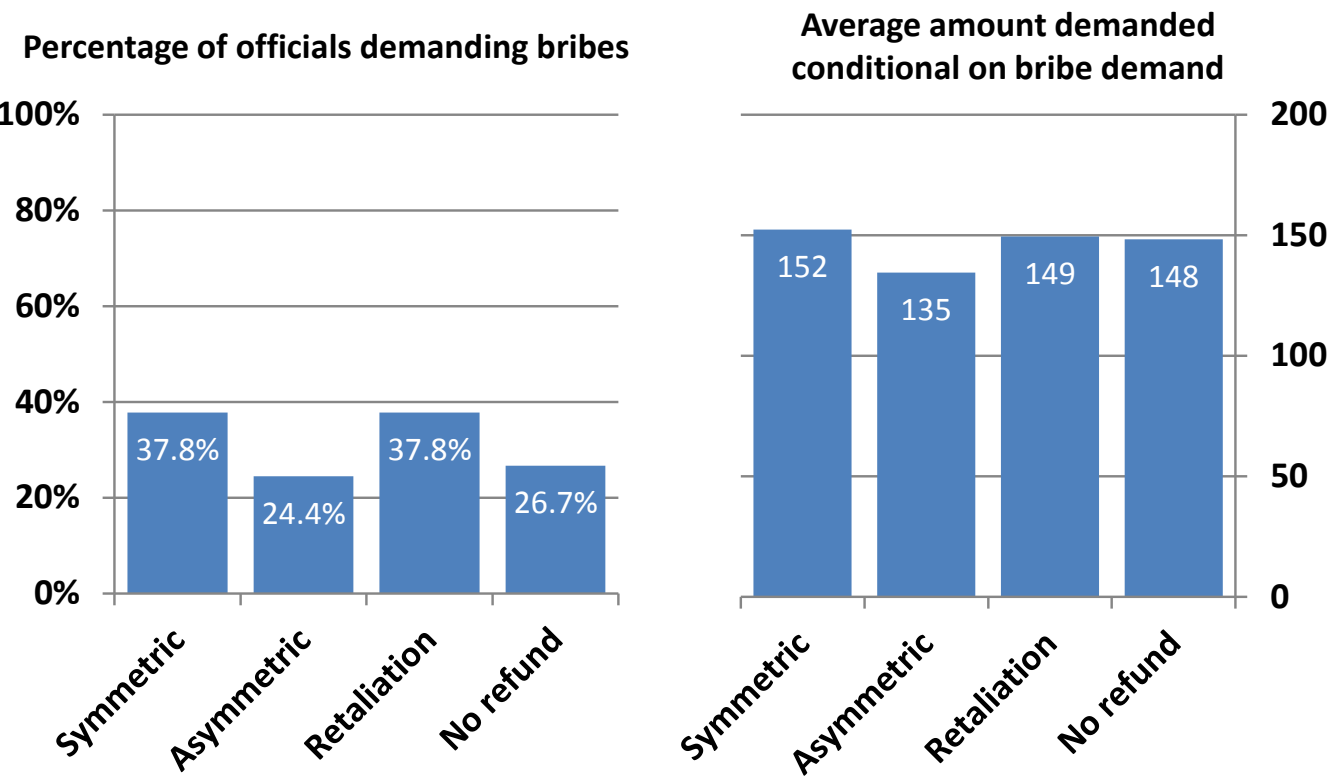

Figure 5. Officials' behavior

We next report results from a probit regression with robust standard errors (see Table 4) that examine the determinants of official behavior, controlling for variables from our post-experiment survey. ${ }^{19}$ Results confirm our earlier observation that asymmetric liability decreases the likelihood of bribe demand compared to the baseline situation of symmetric liability. Interestingly, we find that subjects who report that they are agreeable to giving bribes in the postexperiment survey are significantly more likely to ask for bribes. Also, male subjects seem to ask for more bribes than female subjects, a finding consistent with previous experimental findings (Alatas et al. 2009; Frank, Lambsdorff and

\footnotetext{
${ }^{19}$ In our specification we included controls for religion (Hindu or non-Hindu), as well as interaction terms of the religion dummy with the treatment. Although our results seem to suggest that Hindus ask for bribes significantly more often, we realize that our total sample is relatively small ( 49 out of 147 Hindus ask for a bribe in all the four treatments together, and 8 out of 33 nonHindus ask for a bribe in all the four treatments together) to convincingly conclude whether religion affects the propensity to engage in bribe-taking behavior. Accordingly, we have not reported the dummies related to religion and its interaction with the treatments.
} 
Boehm 2011) as well as other empirical findings (Lambsdorff and Fink 2006). Chi-square tests for mean differences in treatments indicate further that official's behavior is only marginally different between the symmetric and the retaliation treatment; official's behavior is also not significantly different between the retaliation and the no-refund treatments.

Table 4: Probit estimates of Official behavior

\begin{tabular}{|c|c|}
\hline & $\begin{array}{l}\text { Bribe demand } \\
\text { Coefficient (S.E.) }\end{array}$ \\
\hline Symmetric treatment & $2.27 * * *(0.94)$ \\
\hline Retaliation Treatment & $0.90 \quad(0.75)$ \\
\hline No refund treatment & $-0.02 \quad(0.85)$ \\
\hline Nalsar & $-0.42 \quad(0.26)$ \\
\hline University of Hyderabad & $-0.50 \quad(0.32)$ \\
\hline Male & $\mathbf{0 . 4 6 * *}(0.23)$ \\
\hline Scheduled caste & $0.25 \quad(0.33)$ \\
\hline Income (in thousands) & $0.001 \quad(0.003)$ \\
\hline Agreeable to giving bribes & $\mathbf{0 . 6 4} * * *(0.23)$ \\
\hline Age & $0.055 \quad(0.06)$ \\
\hline \multicolumn{2}{|c|}{ Chi-square test for mean treatment differences } \\
\hline Symmetric $=$ Retaliation & $\mathrm{p}$-value $=0.09$ \\
\hline Retaliation $=$ No Refund & $\mathrm{p}$-value $=0.21$ \\
\hline Symmetric $=$ No refund & $\mathrm{p}$-value $=0.01$ \\
\hline Pseudo R square & 0.11 \\
\hline Number of observations & 180 \\
\hline
\end{tabular}


Between the symmetric and the no-refund treatment, there are three features that are different; namely, addition of the asymmetric liability, official's ability to retaliate, and removal of strict monetary incentives for the citizens. Therefore, we cannot discern causality in the difference in officials' behavior between the two treatments. However, the chi-square tests of mean differences establish that officials demand significantly lower bribes compared to the symmetric treatment. We infer from this result that even in the strongest test of the asymmetric liability mechanism, the disciplinary effect remains present.

The question arises whether asymmetric liability affects the profitability of bribe demands. Since we elicited complete strategies from the citizens, we can calculate the expected empirical payoff from each bribe level based on the citizens' propensity to report at every bribe level.

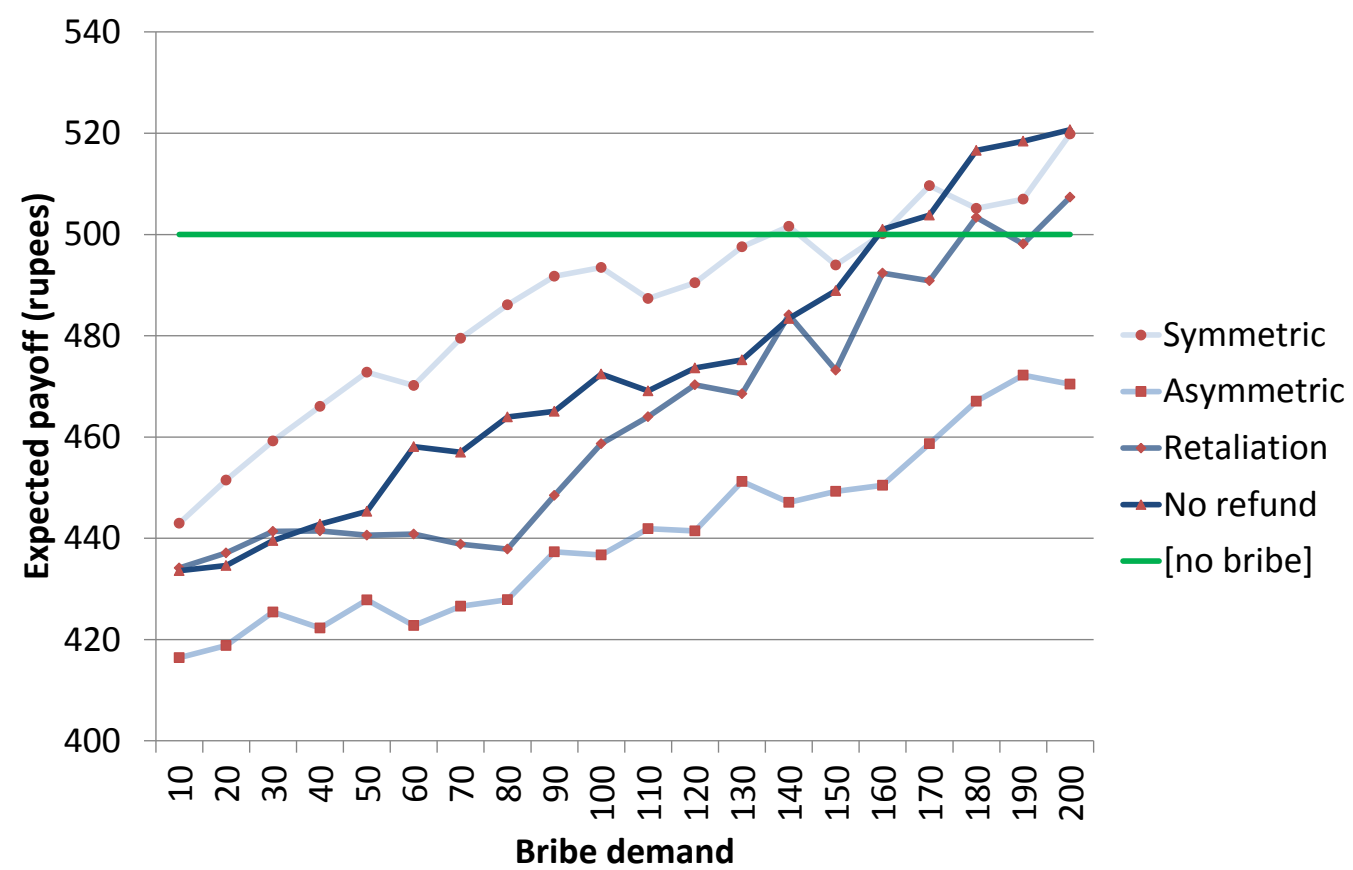

Figure 6. Expected payoff to official conditional on bribe demand 
The results are depicted in Figure $6 .^{20}$ It can be seen that expected payoffs generally increase with the bribe demand. Thus, the citizens' higher propensity to report high bribes is not high enough to offset the officials' extra income from receiving the bribes. In three of the four treatments the most profitable strategy for officials is to demand the maximum bribe. Only in the asymmetric treatment without retaliation, expected payoffs for all bribe levels remain below Rs. 500 that an official would have obtained if he chose not to demand a bribe. This would suggest that for a risk-averse official, not demanding a bribe can be an attractive proposition from payoff considerations alone. Note though, that Figure 6 suggests that for the average bribe of Rs. 150 asked in the experiment, the expected payoffs are lower than what an official could have achieved if he decided to go for the nobribe outcome (Rs. 500). A possible reason for this finding might be that while officials correctly estimate that citizens are less likely to report bribe demands that are not very high (and therefore ask for less than Rs. 200), they underestimate the threshold and ask for smaller than optimal bribes.

\section{Conclusion}

While there has been extensive research on using different ways to fight corruption, the use of citizen reporting as a means of tackling corrupt government officials has received relatively little attention until recently. Whistleblowing by citizens can be particularly useful in situations where the citizen is held hostage by the government official who refuses to provide services that the citizen is entitled to. This corruption situation is characterized by harassment bribes.

Using laboratory experiments, we evaluate the effectiveness of an asymmetric liability policy that provides legal immunity to bribe-givers to encourage whistleblowing. We incorporate two extensions to the basic policy

\footnotetext{
${ }^{20}$ We do not include money officials may spend on retaliation in the expected payoff calculations.
} 
proposal to provide behavioral evidence on the effectiveness of the policy when bribe-takers have the option to retaliate on whistle-blowers if the prosecution is not successful, and the impact of non-monetary incentives in reporting bribe demands.

We find that compared to symmetric liability, allowing legal immunity to the bribe-givers increases reporting of bribe-demands and reduces the demand for bribes. We also find that a substantial minority of citizens refuse to pay bribes, across treatments despite significant monetary costs of doing so. This is not surprising, since refusals to pay may be driven more by principles rather than incentives. An implication of this is that asymmetric liability does not change the moral authority of the law on citizens' behavior and consequently the proposed change in the liability does not have to be interpreted as a "license to bribe".

Comparing behavior in the retaliation and no-refund treatments shows that strict financial incentives do not necessarily drive reporting behavior. Nonmonetary factors can motivate reporting behavior as well. This could be beneficial in the field as monetary incentives (such as return of the bribe money) are often difficult to operationalize.

Analysis of officials' behavior suggests that significant challenges to implementing an asymmetric liability rule emerge when officials are able to retaliate against citizens who report bribe demands. We find that in such situations, both bribe demands and reporting return closer to the original levels of the symmetric liability case.

Our finding suggests that as an anti-corruption measure, asymmetric liability should be implemented along with complementary measures such as policies rotating officials in different posts to mitigate the effectiveness of retaliation against citizens who report bribe demands (see, for example, Abbink 2004). In addition, to protect citizens' vulnerability, whistle blowers may need to 
be given protection such as anonymity for reporters and timely prosecution of the accused. Hence, bolstering the institutional set-up is important to realize the full benefits of this leniency policy.

A related concern with implementing a policy that reduces liability for bribe-givers is that greater reporting may impose large costs on already overburdened judicial systems. Indeed, the incidence of reporting bribery increases in our experiment between the symmetric and asymmetric liability treatments. The costs of prosecuting corruption cases in developing countries are difficult to estimate reliably and if the increase in reporting leads to higher overall costs, then the effectiveness of the mechanism can potentially be reduced. However, while reporting might indeed increase in the short term, we also expect that bribe demands decrease in the longer run. Insofar as citizens' reporting is driven by officials' demands, we should then observe fewer cases of reporting and therefore lower prosecution costs. To ensure that citizens' threat to report remains credible, practical implementation of the policy should perhaps coincide with efforts to reduce costs of reporting, such as greater use of information technology to crowdsource complaints.

Moreover, any leniency policy would need to be implemented in the field with caution. While citizen reporting is useful to identify corrupt officials, citizens themselves could misuse this leniency measure and report honest officials. The focus of our study is on deterring harassment bribes; we did not examine spiteful behavior of citizens when they have the opportunity to report officials. In future research, it would be interesting to explore if citizens report honest officials and attempt to use the asymmetric liability rule for their benefit by harassing the official. 


\section{References}

1. Abbink, K. (2004). Staff rotation as an anti-corruption policy: An experimental study. European Journal of Political Economy, 20(4), 887-906.

2. Abbink, K. (2006). Laboratory experiments on corruption. In: S. RoseAckerman (ed.), International Handbook on the Economics of Corruption. Cheltenham: Edward Elgar.

3. Abbink, K., Brandts, J., Herrmann, B., and Orzen, H. (2010). Inter-group competition and intra-group punishment in an experimental contest game. American Economic Review, 100(1), 420-447.

4. Abbink, K., and Hennig-Schmidt, H. (2006). Neutral versus loaded instructions in a bribery experiment. Experimental Economics, 9(2), 103-121.

5. Abbink, K., Irlenbusch, B., and Renner E. (2002). An experimental bribery game. Journal of Law, Economics, and Organization, 18(2), 428-454.

6. Alatas, V., Cameron, L., Chaudhuri, A., Erkal, N., and Gangadharan, L. (2009). Gender, culture, and corruption: Insights from an experimental analysis. Southern Economic Journal, 75(3), 663-680.

7. Alatas, V., Cameron, L., Chaudhuri, A., Erkal, N., and Gangadharan, L. (2009). Subject pool effects in a corruption experiment: A comparison of Indonesian public servants and Indonesian students. Experimental Economics, 12(1), 113-132.

8. Amegashie, J. (2013). Consumers' Complaints, the Nature of Corruption and Social Welfare. Working Paper.

9. Apesteguia, J., Dufwenberg, M., and Selten, R. (2007). Blowing the whistle. Economic Theory, 31(1), 143-166.

10. Banuri, S., and Eckel, C. (2012). Experiments in culture and corruption: A review. Research in Experimental Economics 15, 51-76. 
11. Banuri, S., Eckel, C., and Wilson, R. (2010). Experimental bribery in context: Comparing the U.S. and Pakistan. Center for Behavioural and Experimental Economic Science, Working Paper \#09-01.

12. Bardhan, P. (1997). Corruption and development: A review of issues. Journal of Economic Literature, 35(3), 1320-1346.

13. Barr, A., and Serra, D. (2009). The effects of externalities and framing on bribery in petty corruption. Experimental Economics, 12(4), 488-503.

14. Basu, K. (2011). Why, for a class of bribes, the act of giving a bribe should be treated as legal. Ministry of Finance Working Paper.

15. Bigoni, M., Fridolfsson, S., Le Coq, C. and Spagnolo, G. (2012). Fines, leniency and rewards in antitrust: An experiment. RAND Journal of Economics, 43(2), 368-390.

16. Brandts, J., and Charness, G. (2011). The strategy versus the direct-response method: A first survey of experimental comparisons. Experimental Economics, $14,375-398$.

17. Callen, M., and Hasanain, A. (2011). The Punjab Model of Proactive Governance: Empowering Citizens through Information Communication Technology. http://odta.net/post/the-punjab-model-of-proactive-governanceempowering-citizens-through-information-communication-

18. Cameron, L., Chaudhuri, A., Erkal, N. and Gangadharan, L. (2009). Propensities to engage in and punish corrupt behaviour: Experimental evidence from Australia, India, Indonesia and Singapore. Journal of Public Economics, 93(7-8), 843-851.

19. Debroy, B. and Bhandari, L. (2012). Corruption in India - The DNA and the RNA, New Delhi: Konark Publishers.

20. Dreze, J. (2011). The bribing game. Indian Express, April 23, 2011.

21. Dufwenberg, M. and Spagnolo, G. (2011). Legalizing bribes. Eller College of Management Working Paper No. 11-09. 
22. Engel, C., Görg, S., and Yu, G. (2012). Symmetric vs. asymmetric punishment regimes for bribery. Legal Studies.

23. Frank, B., and Lambsdorff, J. (2010). Bribing versus gift-giving - An experiment. Journal of Economic Psychology, 31(3), 347-357.

24. Frank, B., Lambsdorff, J., and Boehm, F. (2011). Gender and corruption: Lessons from laboratory corruption experiments. The European Journal of Development Research, 23(1), 59-71.

25. Frey, B. and Oberholzer-Gee, F. (1997) The cost of price incentives: An empirical analysis of motivation crowding-out. American Economic Review, 87(4), 746-755.

26. Gächter, S., Renner, E. and Sefton, M. (2008). The long-run benefits of punishment. Science, 5 December, 322. 1510.

27. Krajcova, J. and Ortmann, A. (2008). Testing leniency programs experimentally: The impact of "natural" framing. CERGE-EI Working Paper Series No. 372.

28. Lambsdorff, J., and Fink, H. (2006). Combating corruption in Colombia: Perceptions and achievements. Passauer Diskussionspapiere No. V-44-06

29. Lowen, A. And Samuel, A. (2012). Bribery and endogenous monitoring effort: An experimental study. Eastern Economic Journal, 38(3), 356-380.

30. Mauro, P. (1995). Corruption and growth. Quarterly Journal of Economics, $110(3), 681-712$.

31. Miron, J. (1999). The effect of alcohol prohibition on alcohol consumption. Retrieved from http://www.nber.org/papers/w7130

32. National Crime Records Bureau (2010) Crime in India: Statistics, Ministry of Home Affairs, New Delhi.

33. Rose-Ackerman, S. (1975). The Economics of Corruption. Journal of Public Economics, 4(2), 187-203. 
34. Rose-Ackerman, S. (1978). Corruption: A Study in Political Economy, New York: Academic Press.

35. Rose-Ackerman, S. (2006). The International Handbook on the Economics of Corruption. Cheltenham: Edward Elgar.

36. Rose-Ackerman, S., and Soreide, T. (2011). The International Handbook on the Economics of Corruption. Volume 2. Cheltenham: Edward Elgar.

37. Schickora, J. (2011). Bringing the four-eye-principle to the lab. Munich discussion paper.

38. Serra, D. (2012) Combining top-down and bottom-up accountability: Evidence from a bribery experiment. Journal of Law, Economics and Organization, 28(3), 569-587.

39. Serra, D. and Wantchekon, L., eds. (2012). New Advances of Experimental Research on Corruption. Research in Experimental Economics, Vol. 15.

40. Shleifer, A., and Vishny, R. (1993). Corruption. Quarterly Journal of Economics, 108(3), 599-617.

41. Transparency International. (2010). Africa Education Watch: Good Governance Lessons for Primary Education.

42. Transparency International (2012) Corruption Perceptions Index.

43. Transparency International (2013) Global Corruption Barometer.

44. Tummala, K.K. (2009). Combating Corruption: Lessons out of India. International Public Management Review 10(1), 34-58

45. van Rijckeghem, C., and Weder, B. (2001). Bureaucratic corruption and the rate of temptation: How much do wages in the civil service affect corruption, and by how much? Journal of Development Economics, 65(2), 307-331. 


\section{Appendix \\ The experimental Instructions \\ (For the Retaliation treatment, other treatments are analogous)}

\section{Player No.}

You have been randomly assigned the role of Citizen/Official in today's experiment.

\section{General}

Welcome to today's economics experiment. This is an experiment in decision making which will provide you an opportunity to earn money. The amount of money you earn depends on your decisions and a randomly matched participant's decisions in the experiment. Your earnings in the experiment will be paid to you in cash privately, at the end of the experiment. Please do not talk to each other during the experiment.

In the experiment you will be matched with another player in the room for the rest of the experiment. You will not know who you are matched with, either during or after the experiment. You and the matched player will be presented with an economic decision-making situation that resembles a real-life situation. One of you will be randomly assigned a role as a Government $\underline{\text { Official, }}$ and the other as a Citizen. You will be provided with a Personal Record Sheet that will state the role you have been assigned in the experiment.

\section{Overview of the Experiment}

In this experiment, the Official can decide to ask the Citizen for a bribe or can decide not to ask the citizen for a bribe. 
If the Official decides to ask for a bribe, then the Official has to choose the amount he wants as bribe from the Citizen. The Citizen then has three options. $\mathrm{S} /$ he can refuse to pay the bribe, pay the bribe, or pay the bribe and report the bribe demand. Reporting the bribe makes it much more likely that the Official is caught and fined.

If the Citizen has reported the bribe, but the authorities have not found sufficient evidence to fine the Official, then the game moves to another stage, in which the Official can reduce the Citizen's income by incurring a cost.

Though the game has up to three stages in which one player needs to make a decision, everybody needs to fill in the decision sheet only once. You will make decisions for every situation in which you can be during the game. We will then collect your decision sheets and pay you according to your decision and the decisions of the other participant you are matched with.

Attached is a Figure which summarizes the structure of the experiment. The sheet labelled "Questions" provides some examples that might help you in understanding the payoffs associated with different decisions. However, before looking at the examples, let us first look at the detailed instructions for each participant.

\section{Detailed Instructions for Officials}

If you are assigned the role of the Official in today's experiment, you have to first decide whether to ask the Citizen for a bribe or not. If you decide not to ask for a bribe, then you get Rs. 500, and the Citizen gets Rs. 500.

If instead, you decide to ask for a bribe, you have to decide how much to ask for. You can ask any amount (B) between 10 and 200 in multiples of Rs. 10. 
The Citizen decides whether or not to refuse to pay the bribe, or to pay the bribe without reporting, or to pay the bribe and report your bribe demand. Reporting determines the probability with which you are fined. If the Citizen does not report the bribe, then the probability of you being fined is $5 \%$. If the Citizen reports the bribe, then this probability increases to $40 \%$.

After the Citizen has decided, a random draw determines whether there is sufficient evidence that you are fined. If there is not sufficient evidence, then you receive Rs. 450 plus the bribe you have asked for. The Citizen receives Rs. 450 less the bribe $\mathrm{s} / \mathrm{h}$ has paid to you. If there is sufficient evidence, then you receive a fine and you must return the bribe and in addition pay a fine. Your payoff after this stage is then Rs. 200. The Citizen gets the bribe back; hence his/her payoff is Rs. 450.

If the Citizen has reported the bribe, but there has not been sufficient evidence, then the game enters a third decision stage. You can spend Rs. 50 from your final earnings to reduce the Citizen's payoff by Rs. 150; in that case, you will receive as your final payments Rs. 400 plus the amount of bribe you had asked for earlier; the Citizen will end up receiving Rs. 300 less the amount of bribe s/he paid to you. If you choose not to reduce the Citizen's payoff, then the final payoffs are the payoffs after stage 2: You receive Rs. 450 plus the bribe, the Citizen receives Rs. 450 less the bribe.

As an Official you make decisions at up to two stages. In the beginning you decide on whether you ask for a bribe and if so, how much you demand. If you decide to ask for a bribe, then it is possible that you need to make another decision at the third stage. In case that the Citizen reports the bribe but you do not get fined you can choose whether or not to reduce the Citizen's payoff. We ask you to make this decision already in the beginning. It is possible that your 
decision for the third stage is not carried out, depending on the decisions of the Citizen and the outcome of the random draw. We nevertheless ask you to make a decision for this case beforehand, such that we do not need to return the decision sheet to you until the game is completed.

\section{Detailed Instructions for Citizens}

If you are randomly assigned the role of the Citizen in today's experiment, it will be the Official who makes a decision first and you respond to it. First the Official decides whether or not to ask for a bribe. If $\mathrm{s} / \mathrm{he}$ does not ask for a bribe, then you get Rs. 500, and the Official gets Rs. 500.

If instead, the Official decides to ask for a bribe, you are told how much the Official asks for.

If the Official asks for a bribe, you have the following options. First, you can refuse to pay the bribe. In this case the game ends and your payoff is Rs. 50; the Official's payoff is Rs. 450. If you decide to pay the bribe, you can decide whether or not to report the Official's bribe demand. Your decision to report determines the probability with which the Official is fined. If you do not report the bribe, then the probability of the Official being fined is $5 \%$. If you report the bribe, then this probability increases to $40 \%$.

After you have decided to pay the bribe, a random draw determines whether there is sufficient evidence that the Official is fined. If there is not sufficient evidence, then you receive Rs. 450 minus the bribe you paid out. The Official receives Rs. 450 plus the bribe you have paid to him/her. If there is sufficient evidence, then you get back the bribe you have paid and your payoff after this stage is Rs. 450 . The Official receives a fine, his/her payoff after this stage is then Rs. 200. 
If you have reported the bribe, but there has not been sufficient evidence, then the game enters a third decision stage. The Official can spend Rs. 50 from his/her final earnings to reduce your payoff by Rs. 150; in that case, you will receive as your final payments Rs. 300 less the amount of bribe you paid to the Official. The Official receives Rs. 400 plus the amount of bribe you have paid to him/her. If the Official chooses not to reduce your payoff, then the final payoffs are the payoffs after stage 2: You receive Rs. 450 less the bribe, the Official receives Rs. 450 plus the bribe.

As a Citizen you make decisions at the second stage, after the Official has decided on the bribe demand. The Official can either not demand a bribe, in which case you do not make a decision. If the Official demands a bribe, s/he can ask for twenty different amounts of bribe from 10 to 200 (in steps of 10). We ask you to make a decision for each bribe amount asked from you beforehand. Your decision sheet comprises a table with all twenty possible amounts. For each amount you tick a box whether you want to refuse to pay the bribe, pay without reporting, or pay and report the bribe demand if the Official demands this amount. We will then collect the Official's decision sheets together with yours, and carry out the decision you specified for the amount the Official has chosen (if any). 


\section{Control Questions}

(These questions aim to help you understand the experiment better and should not be used as a guide for decision-making in the experiment.)

1. Assume that the Official asks for a bribe of Rs. 150. Suppose that the Citizen he is matched with decides to report the bribe and the Official is caught and fined. What will be the earnings of the Official and the Citizen in this group?
a. Official: Rs
b. Citizen: Rs

2. Suppose that the Official asks for a bribe of Rs. 80. The Citizen reports the bribe demand. The Official is not caught however and he decides to spend Rs. 50 to reduce the payoffs of the Citizen. What will be the earnings of the Official and the Citizen in this group?
a. Official: Rs
b. Citizen: Rs

3. What will be the earnings of the Official and the Citizen in the group, if the Official does not ask for a bribe?
a. Official: Rs
b. Citizen: Rs

4. Suppose that the Official asks for a bribe of Rs. 200. The Citizen does not report the bribe demand. The Official is not caught. What will be the earnings of the Official and the Citizen in this group?

a. Official: Rs 
b. Citizen: Rs

5. Suppose that the Official asks for a bribe of Rs. 100. The Citizen refuses to give the bribe. What will be the earnings of the Official and the Citizen in this group?
a. Official: Rs
b. Citizen: Rs 


\section{Post-Experiment Survey}

Player Number:

Instructions: Please answer ALL of the questions on this survey as accurately as you can. All responses will be kept confidential by the researchers and will not be revealed to any authorities within the university or outside. Leave blank if you do not wish to answer.

1. What is your date of birth?

Month: Year:

2. What is your gender?

- Male

- Female

3. What is your religion?

- Hindu

- Muslim

- Christian

- Sikh

- Other (Please specify

- Don't know

4. What is your caste?

- Scheduled caste

- Scheduled tribe

- Other backward classes 
- Upper caste

- Other (Please specify

- Don’t know

5. What is your program and year of study at the University or Institute? (Mark only one)

- Bachelor's student (BA, BSc, BE, etc.)

- Circle Year $1 / 2 / 3 / 4 / 5$

- Master's student (MPhil, MA, MSc, MTech, MBA, LLB etc.)

- Circle Year $1 / 2 / 3 / 4 / 5$

- Other (Please specify

6. What is your field of study (specialization) in the program?

7. Last year, what were your average marks/grades in the program? out of

8. How much work experience do you have? (Mark all that apply)

- None

- Internship months. Employer(s):

- Full-time work years. Employer(s):

9. In the last year, how much did you earn? Include all sources. Rs. 
10. What were the source(s) of this income? (Mark all that apply)

- Employment (part-time/ fulltime job)

- Allowance from family

- Scholarships

- Other (Please specify

11. How do you most hear about corrupt behaviour? (Mark only one)

- Through personal experience.

- Through the experiences of family or friends

- By reading magazines or the newspaper

- By listening to the news on TV or radio

- Through an academic course

- Other (Please specify

12. In what context do you most hear about corrupt behaviour? (Mark only one)

- Corruption scandals involving politicians and bureaucrats

- Corruption scandals involving companies and rich individuals

- Harassment of ordinary people for basic services

- Other (Please specify )

13. In what context do you most experience corrupt behaviour? (Mark only one)

- I receive poorer quality public infrastructure because of corruption

- Other people get ahead in education and career because of corruption

- I have to give bribes frequently for basic government services

- I have to give bribes frequently for services by private service providers

- I have to give bribes occasionally for basic government services

- I have to give bribes occasionally for services by private service providers 
- Other (Please specify

14. In which contexts have you ever given a bribe? (Mark all that apply)

- To get household services such as electricity, water or telephone connection

- To get services in a bank, post office, insurance company or transport office

- To get educational services at a school, college or for a scholarship

- Other (Please specify )

- I have never given a bribe

15. Which of the following best describes the anti-corruption law in India? (Mark only one)

- If caught, both the bribe giver and taker are committing an illegal act

- If caught, the bribe taker is committing an illegal act, but the bribe giver is not responsible

- If caught, the bribe giver is committing an illegal act, but the bribe taker is not responsible

- If caught, neither the bribe giver nor taker are committing an illegal act

- I don't know anything about the anti-corruption law in India

16. Do you think that it is useful to have a system where there is a way to get what you want even if you have to bribe? (Mark only one)

- Yes

- No

- Don't know

17. In which of the following situations have you jumped or cut a queue? (Mark all that apply) 
- While waiting to buy a ticket

- Boarding a bus

- Boarding a train

- In government offices

- Waiting at the bank teller 